\title{
Erratum to: Nanoscale composite materials in the system $\mathrm{SiO}_{2-}$ $\mathrm{TiO}_{2}$
}

\author{
A. N. Murashkevich • O. A. Alisienok • \\ I. M. Zharskiy $\cdot$ E. K. Yukhno
}

Published online: 3 December 2013

(c) Springer Science+Business Media New York 2013

\begin{abstract}
Nanoscale composite materials based on the $\mathrm{SiO}_{2}-\mathrm{TiO}_{2}$ system were prepared in the form of co-precipitated composites and core $\mathrm{SiO}_{2}-$ shell $\mathrm{TiO}_{2}$ composites, with specific surface area $150-650 \mathrm{~m}^{2} / \mathrm{g}$ and sorption volumes $0.1-1.0 \mathrm{~cm}^{3} / \mathrm{g}$. It is shown that variation of phase composition and morphology permits to change their structural-adsorption properties and nanocrystallites size after thermal treatment. It is discovered that co-precipitated composite materials differ from core $\mathrm{SiO}_{2}$-shell $\mathrm{TiO}_{2}$ composites by a component interaction degree. It determines the difference of the titan-containing component crystallization process and alteration of their structuralabsorption properties after thermal treatment. The results of the tests of composites as photocatalysts for Rhodamine B decomposition reaction, as catalysts of Hantzsch and Biginelli reaction, and as fillers in electrorheological fluids are shown.
\end{abstract}

Keywords Composite $\cdot \mathrm{SiO}_{2}-\mathrm{TiO}_{2}$ system . Photocatalysis · Electrorheology $\cdot$ Cardiotropic drugs

The online version of the original article can be found under doi:10. 1007/s10971-012-2947-8.

This article was submitted to be part of this special issue, but was previously published in Volume 65 , Number 3 of the journal. It is reprinted here in its entirety.

A. N. Murashkevich $(\bowtie) \cdot$ O. A. Alisienok .

I. M. Zharskiy · E. K. Yukhno

Belarusian State Technological University, Minsk, Belarus

e-mail: man@bstu.unibel.by

\section{Introduction}

Nowadays individual nanoscale titania and silica are well studied, both in terms of describing their properties and preparation technologies. Their world production is estimated in tens of million tons [1,2], and the practical use allows to solve a number of problems of heterogeneous catalysis and photocatalysis [3-5]. Being ingredients of composite materials, they successfully serve as fillers, carriers of catalytically active components, selective sorbents [6,7], etc. Less studied are the composite materials in the system $\mathrm{SiO}_{2}-\mathrm{TiO}_{2}$, although they are known to exist in several different morphologies: co-precipitated powders, xerogels, mesostructured composite materials with the "core-shell" morphology, where each of the components with equal probability can act as the core or the shell [8]. Various methods of obtaining such composite materials are determined not only by the nature of the interaction between different components [9, 10], but also by resistance to thermal stress [11], various surface properties, which open new perspectives and possibilities for their practical application [12-19].

The aim of this work was to study production conditions of $\mathrm{SiO}_{2}-\mathrm{TiO}_{2}$ composite nanomaterials of various composition and morphology using precursors of organic-mineral origin and to assess their performance-functional characteristics.

\section{Experimental}

Composites based on $\mathrm{SiO}_{2}-\mathrm{TiO}_{2}$ nanooxides were obtained by methods of homogeneous and oriented deposition in the form of co-precipitated powders and materials with "core $\mathrm{SiO}_{2}$-shell $\mathrm{TiO}_{2}$ " morphology. 
Co-precipitated composites were prepared by mixing silicon- and titanium-containing components. Titanium and silicon alkoxides, as well as inorganic derivatives - liquid glass $(\mathrm{M}=2.4)$, solutions of titanium trichloride in $\mathrm{HCl}$ and titanium tetrachloride in isopropyl alcohol, $\mathrm{SiO}_{2}$ and $\mathrm{TiO}_{2}$ sols were used as initial compounds. To obtain $\mathrm{TiCl}_{3}$ solution, titanium powder was dissolved in $\mathrm{HCl}$, then oxidation of $\mathrm{Ti}^{+3}$ to $\mathrm{Ti}^{+4}$ by nitric acid was performed. The process of $\mathrm{TiO}_{2}$ sol preparation consisted of several stages: hydrated titania precipitation from a titanium tetrachloride solution by ammonium carbonate solution, with subsequent precipitate peptization in the presence of nitric acid [20]. Silica sol was prepared from fluorosilicate acid solutions (12-14 wt. \%) by calcium carbonate suspension addition and then separating calcium fluoride precipitate from $\mathrm{SiO}_{2}$ sol in a centrifuge. Titania and silica concentration in the sols varied in the range of 2-3 wt. \%. Mixing of the sols with a given mass ratio was carried out at room temperature. In order to improve the structural and sorption characteristics the structure-forming agent was injected at the stage of sols mixing.

Composites “core $\mathrm{SiO}_{2}-$ shell $\mathrm{TiO}_{2}$ ” Microspherical silicon dioxide to be used as the composite core was precipitated from aqueous solutions of sodium silicate $(2.4 \mathrm{~mol} / \mathrm{l})$ with a solution of ammonium carbonate or acetate and ammonia. Alternatively, microspherical silicon dioxide was precipitated from water-ethanol solutions of tetraethoxysilane (TEOS) by a modified Stöber method using dodecylamine as the template. By varying initial synthesis conditions and employing the structure-forming agent, it was possible to vary the specific surface area of the core between 180 and $700 \mathrm{~m}^{2} / \mathrm{g}$ and to control the particle size in the 300-700 nm range. The composite was doped by introducing an aqueous solution of phosphoric acid (0.5-5 wt. $\% \mathrm{P}_{2} \mathrm{O}_{5}$ ) before the heat treatment of the samples.

\subsection{Characterization of materials}

The $\mathrm{TiO}_{2}$ content of the materials was measured photocolorimetrically. The textural and adsorption properties of the materials were determined by adsorption gravimetry using nitrogen or phenol (the latter dissolved in n-heptane) as the adsorbate. The specific surface area of the $\mathrm{TiO}_{2}$ shell of the composite was calculated from the specific surface area of the core and that of the composite as a whole using the additivity rule. X-ray diffraction patterns were obtained on DRON-3 diffractometer (Nifiltered $\mathrm{CuK}_{\alpha}$ radiation) at room temperature in the $2 \theta=11^{\circ}$ $70^{\circ}$ range at the scanning rate of $2 \% \mathrm{~min}$. Crystallite size $\mathrm{D}, \mathrm{nm}$, was evaluated using the Scherrer equation.

IR spectroscopic studies were performed using FT-IR spectrometer NEXUS NICOLET. The mass of the composite test sample was about $1 \mathrm{mg}$, which corresponds to $0.1 \%$ of the tablet $\mathrm{KBr}$.
The amount of the amorphous titanium-containing component in the heat-treated material was determined by the acid dissolution method based on the difference between the solubilities of crystalline and amorphous $\mathrm{TiO}_{2}$ in sulfuric acid [21]. The composite samples were placed in a $1 \mathrm{M}$ sulfuric acid solution in ratio solid: liquid $=1: 300$ and were held there for $24 \mathrm{~h}$. Thereafter, the titania that had passed into the solution was quantified in the filtrate by photocolorimetry.

The electrokinetic potential was measured by macroelectrophoresis at different $\mathrm{pH}$ values of the sample suspensions without the background electrolyte to determine the isoelectric point (IEP) position. The electrosurface characteristics were used as a diagnostic tool in assessing the resulting composite morphology. The analogy of the composite "core $\mathrm{SiO}_{2}$-shell $\mathrm{TiO}_{2}$ " and titania $(\mathrm{pH}$ $\mathrm{IEP}=6$ ) electrosurface properties proves the formation of a composite material with a specified morphology and degree of the silica core screening by the titania shell.

To assess the electrorheological properties there were prepared electrorheological dispersions containing different amounts of the filler (composites were used as fillers), and transformer oil as a dispersion medium. The fillers had previously been dried to constant weight at $120{ }^{\circ} \mathrm{C}$. Rheological measurements were performed on rheometer Physica MCR 301 Anton Paar company. The measuring cell of the type plate-plate with the plate's diameter $50 \mathrm{~mm}$ and the gap between the plates $1 \mathrm{~mm}$ was used. The speed of rotation of the upper plate or the inner cylinder, which determines the liquid shear rate was set. The measured torque acting on the plate or cylinder was used to calculate the shear stress. The density of the current passing through the electrorheological variance was also measured.

The photocatalytic activity of the composites was measured in the degradation of Rhodamine B dye under the action of UV radiation without focusing on intermediate degradation products. The commercial dye was used as received. The source of UV radiation was a DRSh 250-3 ultrahigh-pressure mercury lamp. The initial dye concentration was $10^{-5} \mathrm{~mol} / \mathrm{l}$, and the photocatalyst concentration was $10^{-3}$ wt. $\%$. Photocatalytic activity was evaluated as the decrease in the dye concentration during the process. The preliminary studies have shown no dye physical adsorption on the investigated photocatalysts. To do this, the reaction mixture was sampled at intervals, the catalyst was separated out, and the extinction coefficient of the samples was measured on a KFK-3 photocolorimeter at a wavelength of $566 \mathrm{~nm}$, which corresponds to the absorbance maximum of the dye. Rate constants were calculated under the assumption that the dye degradation reaction is first-order. This assumption is confirmed by extensive experimental data on the degradation of organic dyes, 
Table 1 Conditions of production and properties of composites produced by cohydrolysis of silicon- and titanium-containing components

\begin{tabular}{|c|c|c|c|c|c|}
\hline $\mathrm{Ti}$ and $\mathrm{Si}$ containing components & $\begin{array}{l}\text { Oxides ratio } \\
\left(\mathrm{TiO}_{2}: \mathrm{SiO}_{2}\right),(\text { mas. \%) }\end{array}$ & $\begin{array}{l}\mathrm{S}_{\mathrm{sp}} \\
\left(\mathrm{m}^{2} / \mathrm{g}\right)\end{array}$ & $\mathrm{V},\left(\mathrm{cm}^{3} / \mathrm{g}\right)$ & $\begin{array}{l}\mathrm{d}=4 \mathrm{~V} / \mathrm{S} \\
(\mathrm{nm})\end{array}$ & Comment \\
\hline TIPT, TEOS $\mathrm{NH}_{4} \mathrm{OH}$ & $10: 90$ & $146-323$ & 0.54 & $17.0\left({ }^{\mathrm{a}} 126\right)$ & $v\left(\mathrm{NH}_{4} \mathrm{OH}\right) / v(\mathrm{TEOS})=11$ \\
\hline TIPT, TEOS & $50: 50$ & $170-378$ & 0.08 & $2.0\left({ }^{\mathrm{a}} 160\right)$ & - \\
\hline TIPT, TEOS & $90: 10$ & $200-302$ & - & - & - \\
\hline $\mathrm{TiCl}_{3}$ in $\mathrm{HCl}$, water glass & $10: 90$ & $250-450$ & 0.18 & $1.5\left({ }^{\mathrm{a}} 446\right)$ & Ablution by $\mathrm{CH}_{3} \mathrm{COOH}$ solution \\
\hline $\mathrm{TiCl}_{3}$ in $\mathrm{HCl}$, water glass, $\left(\mathrm{NH}_{4}\right)_{2} \mathrm{CO}_{3}$ & $90: 10$ & $176-200$ & - & - & \\
\hline $\mathrm{TiCl}_{3}$ in $\mathrm{HCl}$, water glass, $\left(\mathrm{NH}_{4}\right)_{2} \mathrm{CO}_{3}$ & $50: 50$ & $160-290$ & 0.29 & $5.2\left({ }^{\mathrm{a}} 227\right)$ & \\
\hline $\mathrm{TiCl}_{4}$, water glass, $\left(\mathrm{NH}_{4}\right)_{2} \mathrm{CO}_{3}$ & $50: 50$ & $250-270$ & - & - & - \\
\hline
\end{tabular}

a $\mathrm{S}_{\mathrm{sp}}\left(\mathrm{m}^{2} / \mathrm{g}\right)$ value used in the pore diameter calculation

Table 2 Synthesis conditions and the results of the study of $\mathrm{SiO}_{2}-$ $\mathrm{TiO}_{2}$ samples, obtained from $\mathrm{SiO}_{2}$ and $\mathrm{TiO}_{2}$ sols

\begin{tabular}{lllll}
\hline $\begin{array}{l}\text { Sample } \\
\text { number }\end{array}$ & $\begin{array}{l}\text { Oxides ratio } \\
\left(\mathrm{TiO}_{2}: \mathrm{SiO}_{2}\right), \\
\text { mas. \% }\end{array}$ & $\begin{array}{l}\text { Template, } \\
\text { mass ratio } \\
\text { composite:template }\end{array}$ & $\begin{array}{l}\mathrm{S}_{\mathrm{sp}}, \\
\left(\mathrm{m}^{2} / \mathrm{g}\right)\end{array}$ & $\begin{array}{l}\mathrm{V}, \\
\left(\mathrm{cm}^{3} / \mathrm{g}\right)\end{array}$ \\
\hline 1 & $10: 90$ & - & 403 & - \\
2 & $50: 50$ & - & 280 & - \\
3 & $90: 10$ & - & $140^{\mathrm{a}}\left(153^{\mathrm{b}}\right)$ & 0.086 \\
4 & $10: 90$ & DDA, 1:1.5 & $623(655)$ & 0.933 \\
5 & $50: 50$ & DDA, 1:1.5 & $492(519)$ & 0.634 \\
6 & $50: 50$ & DDA, 1:0.2 & $349(435)$ & 0.218 \\
7 & $90: 10$ & DDA, 1:1.5 & $220(213)$ & 0.169 \\
8 & $90: 10$ & DDA, 1:0.1 & 139 & - \\
9 & $50: 50$ & PEPA, 1:1 & 364 & - \\
10 & $50: 50$ & DEA, 1:1 & 375 & - \\
11 & $90: 10$ & HMTA, 1:1.5 & 192 & - \\
12 & $90: 10$ & HMTA, 1:0.2 & 173 & - \\
13 & $90: 10$ & HMTA, 1:0.1 & 131 & - \\
\hline
\end{tabular}

Thermal treatment: $1-3$ - drying at $120{ }^{\circ} \mathrm{C}$ up to fixed-mass; 4-13drying at $150{ }^{\circ} \mathrm{C}$ up to fixed-mass, calcination $3 \mathrm{~h}$ at $550{ }^{\circ} \mathrm{C}$

$D D A$ dodecylamine, PEPA polyethylenpolyamine, DEA diethylamine, HMTA hexamethylentetramine

a Specific surface area, determined by phenol adsorption from solution in n-heptane

b Specific surface area, determined by nitrogen adsorption

including Rhodamine $\mathrm{B}$, in the presence of irradiated titania [22-24].

Investigation of composites catalytic properties in the reactions of Hantzsch and Biginelli was carried out in the laboratory of heterocyclic compounds Institute of Organic Synthesis Ural Division of RAS [25, 26].

\section{Results and discussion}

Tables 1, 2 and 3 show the results of investigating the properties of $\mathrm{SiO}_{2}-\mathrm{TiO}_{2}$ composites with different oxides mole ratio, silicon - and titanium-containing components nature, mixing order, templates presence. It resulted in production of composite materials with different composition, morphology, structural and adsorption characteristics.

Analyzing the results presented in Table 1, it can be noted that the composite dispersion depends primarily on the initial component ratio, their concentration, dispersion medium $\mathrm{pH}$, which is specifically modified using sodium carbonate and ammonium hydroxide solution and, to a less extent, on the precursors nature. In this case, we observe that the product preparation proceeded mainly not on the sol-gel scheme, but on the mechanism of deposition with a considerable influence of the coagulation process on the secondary particle aggregates formation.

The results given in Table 2 indicate that the use of templates and structure-forming agents allow to significantly change the structural-adsorption characteristics of composite materials, especially, their adsorption volume. Therefore, the preferred method is the one which is based on a mixture of sols not containing strange ions, which can, alongside with the structure-forming agent influence, change the structural-adsorption characteristics of the composite, as in the case of co-hydrolysis of the initial components. However, in mixing the sols of $\mathrm{SiO}_{2}$ and $\mathrm{TiO}_{2}$ there is very little probability to achive the mixing of components on the molecular level.

Our method of forming the "core $\mathrm{SiO}_{2}-$ shell $\mathrm{TiO}_{2}$ " composite is based on the heteroadagulation effect when particles of titania sol (particle size is $10-15 \mathrm{~nm}$ ) with the positive charge of the surface at a dispersion medium certain $\mathrm{pH}$ are attracted to the negatively charged silica particles of a much larger size $(300-500 \mathrm{~nm})$. It is discovered that successful implementation of the electrostatic mechanism occurs not at the stage of the initial components mixing, which $\mathrm{pH}$ values should be maintained at the level of $1-1.5$, but at the subsequent rise of the dispersion medium $\mathrm{pH}$ to $4-5.3$. It is at this stage that effective recharging the silica particles surface from a positive sign 
Table 3 Synthesis conditions and properties of "core $\mathrm{SiO}_{2}-$ shell $\mathrm{TiO}_{2}$ " composites

\begin{tabular}{|c|c|c|c|c|c|c|}
\hline \multirow{2}{*}{$\begin{array}{l}\text { Sample } \\
\text { number }\end{array}$} & \multicolumn{3}{|c|}{ Synthesis conditions } & \multicolumn{3}{|c|}{ Composite properties } \\
\hline & $\begin{array}{l}\mathrm{d}_{\mathrm{TiO} 2}, \\
(\mathrm{~nm})\end{array}$ & $\begin{array}{l}\mathrm{S}_{\mathrm{sp}} \\
\left(\mathrm{m}^{2} / \mathrm{g}\right)\end{array}$ & $\begin{array}{l}\text { Precipitation } \\
\mathrm{pH}\end{array}$ & $\mathrm{pH}$ & $\mathrm{TiO}_{2}, \%$ & $\begin{array}{l}{ }^{\mathrm{a}} \mathrm{S}_{\mathrm{sp}}(\text { composite/shell }), \\
\left(\mathrm{m}^{2} / \mathrm{g}\right)\end{array}$ \\
\hline 1 & 10 & 197 & 4.0 & 4.8 & 26.5 & $266\left(377^{b}\right) / 457$ \\
\hline 2 & 24 & & & 3.8 & 29.6 & $262 / 364$ \\
\hline 3 & 42 & & & 3.5 & 29.9 & $275 / 458$ \\
\hline 4 & 13 & 182 & 3.0 & 5.2 & 26.2 & $191 / 216$ \\
\hline 5 & & & 3.7 & 3.8 & 28.3 & $223 / 327$ \\
\hline 6 & & & 4.2 & 4.6 & 27.4 & $204 / 262$ \\
\hline 7 & & & 5.6 & 5.9 & 27.8 & $242 / 398$ \\
\hline 8 & 12 & 189 & 4.5 & 4.3 & 8.2 & $119 /-$ \\
\hline 9 & & & 4.4 & 5.4 & 18.4 & $165 / 59$ \\
\hline 10 & & & 4.8 & 4.8 & 25.4 & $220 / 311$ \\
\hline 11 & & & 4.5 & 5.3 & 32.8 & $185 / 177$ \\
\hline 12 & & & 4.8 & 3.7 & 44.6 & $192 / 196$ \\
\hline 13 & 12 & 182 & 4.7 & 4.8 & 25.4 & $220 / 311$ \\
\hline 14 & & 268 & & 4.8 & 29.6 & $366 / 711$ \\
\hline 15 & & $677^{\mathrm{c}}$ & & 4.8 & 22.1 & $445\left(503^{\mathrm{b}}\right) /-$ \\
\hline
\end{tabular}

a Specific surface area, determined by phenol adsorption from solution in n-heptane

b Specific surface area, determined by nitrogen adsorption

c $\mathrm{SiO}_{2}$ core prepared by modified Stöber method

to negative, occurs, and they begin to attract titania sol particles, which at the dispersion medium $\mathrm{pH}$ less then 6 remain positively charged.

The most essential factors determining the probability of forming the composite of specified morphology and its properties are:

titania sol particles size and their surface charge, dispersion medium initial and final $\mathrm{pH}$ after component mixing, and finally, dispersivity of the silica core, which, as shown by the results of experiments $13-15$ (Table 3 ) is one of the most important factors in regulating the structuraladsorption and surface properties of the composite shell. Increase of the composite shell dispersivity and the composite as a whole by increasing the core dispersivity is less important than by introduction of templates and structurebuilding agents, which is understandable due to differences in the influence mechanism.

The obtained sample IR-spectra vividly reflect the effect of the composite content and morphology on the state of the components inside the composite, and the degree of their interaction. The IR-spectra are given in Fig. 1, and the samples characteristics-in Table 4.

The IR-spectra of co-precipitated nanocomposite materials (curves 4-6, Fig. 1) together with the absorption bands characteristic of the individual titania and silica, exhibits the presence of the absorption band in the range of 928-949 $\mathrm{cm}^{-1}$, which refers to the characteristic vibrations of $\mathrm{Si}-\mathrm{O}-\mathrm{Ti}$ bonds [9]. At the same time, the "core $\mathrm{SiO}_{2}-$

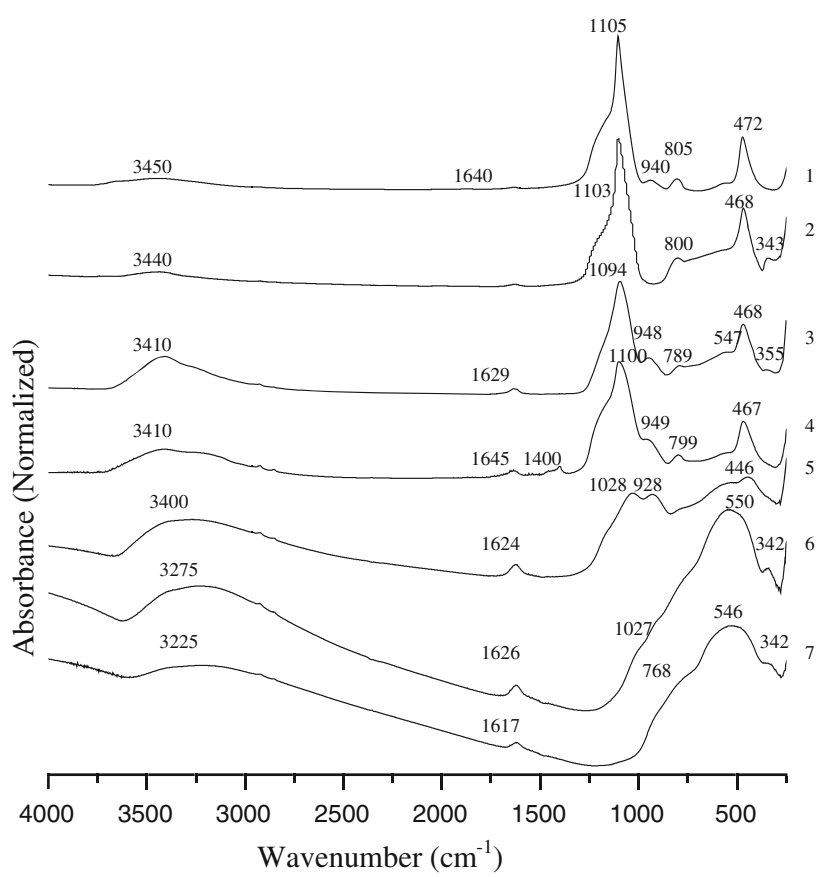

Fig. 1 IR absorbance spectra of $\mathrm{TiO}_{2}-\mathrm{SiO}_{2}$ composites and individual silica and titania (sample number corresponded to Table 4)

shell $\mathrm{TiO}_{2}$ " composite in this range does not contain a similar absorption band (curve 2, Fig. 1), which is associated with an isolated state of composite components; the spectrum reveals this by absorption bands proper only the individual oxides. In the composite spectrum (Fig. 1, curve 
Table 4 Synthesis conditions and properties of titanium and silicon individual oxides and $\mathrm{SiO}_{2}-\mathrm{TiO}_{2}$ composites

\begin{tabular}{lllll}
\hline $\begin{array}{l}\text { Sample } \\
\text { number }\end{array}$ & Initial components & $\begin{array}{l}\text { Molar ratio, } \\
\mathrm{H}_{2} \mathrm{O}:\left(\mathrm{TiO}_{2}+\mathrm{SiO}_{2}\right)\end{array}$ & $\begin{array}{l}\text { Solid phase concentration, in } \\
\text { converting to oxides, mas. \% }\end{array}$ & $\begin{array}{l}\mathrm{TiO}_{2}: \mathrm{SiO}_{2} \\
\text { ratio, (mas. \%) }\end{array}$ \\
\hline 1 & TEOS, $\mathrm{NH}_{4} \mathrm{OH}$ & 169.0 & 0.4 & $0: 100$ \\
2 & Precipitated $\mathrm{SiO}_{2}, \mathrm{TiO}_{2}$ sol & 76.5 & 4.5 & $30: 70$ \\
3 & $\mathrm{TiO}_{2}$ and $\mathrm{SiO}_{2}$ sols & 149 & 0.5 & $45: 55$ \\
4 & TIPT, TEOS, $\mathrm{NH}_{4} \mathrm{OH}$ & 71.0 & 0.5 & $12: 88$ \\
5 & TIPT, TEOS & 12.5 & 1.7 & $50: 50$ \\
6 & TIPT, TEOS & 6.1 & 1.7 & $92: 8$ \\
7 & TIPT & 14.4 & 1.7 & $100: 0$ \\
\hline
\end{tabular}

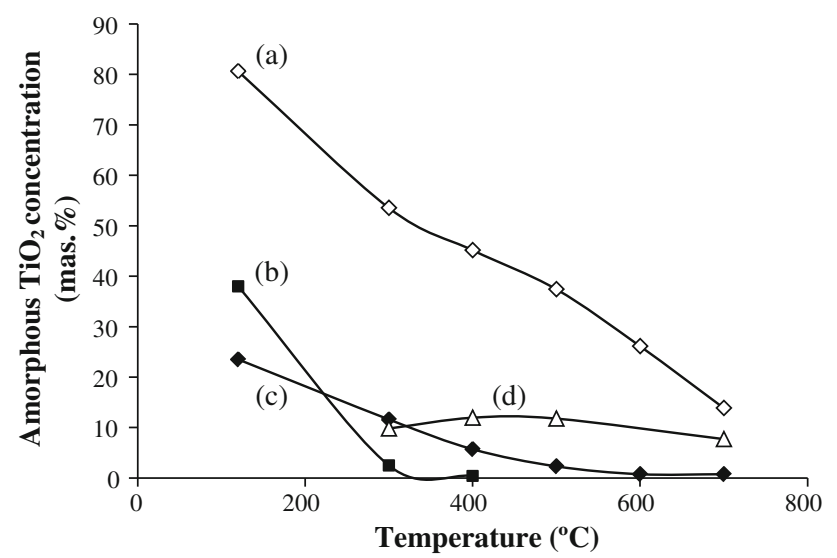

Fig. 2 Concentration of amorphous $\mathrm{TiO}_{2}$ in $\mathrm{SiO}_{2}-\mathrm{TiO}_{2}$ nanooxides after thermal treatment for (a) co-precipitated composite, $(b)$ individual $\mathrm{TIO}_{2},(c)$ core-shell composite, $(d)$ composite, obtaned from silica and titania sols

3) derived from $\mathrm{TiO}_{2}$ and $\mathrm{SiO}_{2}$ sols, in contrast to the coprecipitated sample with a similar ratio of oxides there was revealed an absorption bond in the range of $355 \mathrm{~cm}^{-1}$ due to the presence of amorphous titania, that supports different states of components in these composites.

It should be noted that the composite materials in $\mathrm{SiO}_{2}-$ $\mathrm{TiO}_{2}$ system are highly hydrophilic, and this property increases with augmentation of titania content. In this case, IR-spectra show increase of intensity, broadening of vibrational bands of water and displacement of the peak in the low frequency range up to $3346 \mathrm{~cm}^{-1}$, as well as increasing frequency of bending vibrations of water from 1626 to $1634 \mathrm{~cm}^{-1}$. This testifies not only to the water content increase, but also to increase of hydrogen bonds energy in double nanoxides due to titania coordination features. Our data suggest that double nanooxides are more prone to sorption processes, than individual ones.

At heat treatment of $\mathrm{SiO}_{2}-\mathrm{TiO}_{2}$ nanocomposites the following processes occur: dehydration, which depth depends mainly on the treatment temperature, oxides interaction, titania crystallization, complicated by silica presence. Fig. 2 shows the results of the evaluation of amorphous titania in the composites of different morphology depending on the treatment temperature. Table 5 presents changes of titania crystallites form and size.

Silica most strongly affects titania crystallization in coprecipitated composites since in this case the initial homogenization degree of components is the highest. This is also confirmed by a higher content of amorphous titania in the composite in the studied temperature range (curve a, Fig. 2) and by the results given in Table 5. At the same time, the composite obtained from the $\mathrm{SiO}_{2}$ and $\mathrm{TiO}_{2}$ sols, as well as the core-shell $\mathrm{SiO}_{2}-\mathrm{TiO}_{2}$ composite, have similar values for amorphous titania content, especially at the beginning of the crystallization process at $300^{\circ} \mathrm{C}$, which is an additional proof of greater isolation of components in these composites in comparison with the coprecipitated ones.

Figure 3 illustrates temperature effect on the specific surface area at $\mathrm{SiO}_{2}-\mathrm{TiO}_{2}$ nanocomposite materials. Along with the trend of decreasing surface area at increasing treatment temperature there can be noted a number of peculiarities.

The largest specific surface area of a dried product is characteristic of nanocomposites obtained from $\mathrm{SiO}_{2}$ to $\mathrm{TiO}_{2}$ sols, but its maximum value is not that for a dried sample, and for a heated one at $\mathrm{T}=400-450{ }^{\circ} \mathrm{C}$, which is not typical of other varieties of composites. There is some increase of amorphous titania amount in this sample at such temperatures (curve a, Fig. 2), it is probably due to increase in the components interaction degree, which is accompanied by partial amorphization of the product and increase of its dispersivity, respectively. The maximum thermal stability of the specific area for co-precipitated composites, with the most noticeable silica effect on crystallization of titania.

As indicated in Fig. 4, curve a, titania nanozol is most active as a photocatalyst and the results of spectroscopy reveal a complete solution bleaching already within $20 \mathrm{~min}$. It was found that in the presence of the sol Rhodamine B complete decomposition occurs when irradiated 
Table 5 Influence of thermal treatment temperature on titania nanocrystallite size

\begin{tabular}{|c|c|c|c|c|c|c|}
\hline \multirow[t]{2}{*}{$\mathrm{T},{ }^{\circ} \mathrm{C}$} & \multicolumn{2}{|l|}{$\mathrm{TiO}_{2}$} & \multicolumn{2}{|c|}{ Core $\mathrm{SiO}_{2}$-shell $\mathrm{TiO}_{2}\left(30\right.$ mas. $\left.\% \mathrm{TiO}_{2}\right)$} & \multicolumn{2}{|c|}{ Co-precipitated $\mathrm{SiO}_{2}-\mathrm{TiO}_{2}\left(30\right.$ mas. $\left.\% \mathrm{TiO}_{2}\right)$} \\
\hline & $\begin{array}{l}\text { Crystalline } \\
\text { modification }\end{array}$ & $\mathrm{D}_{\mathrm{cr}}, \mathrm{nm}$ & $\begin{array}{l}\text { Crystalline } \\
\text { modification }\end{array}$ & $\mathrm{D}_{\mathrm{cr}}, \mathrm{nm}$ & $\begin{array}{l}\text { Crystalline } \\
\text { modification }\end{array}$ & $\mathrm{D}_{\mathrm{cr}}, \mathrm{nm}$ \\
\hline 300 & Anatase & 12 & Anatase & - & Amorphous & - \\
\hline 400 & & 13 & & 7 & & \\
\hline 500 & & 23 & & 8 & & \\
\hline 600 & & 27 & & 9.5 & & \\
\hline 700 & Rutile & 40 & & 14 & & \\
\hline \multirow[t]{2}{*}{800} & & 78 & Anatase & 19 & Anatase & 5 \\
\hline & & & Rutile & - & & \\
\hline \multirow[t]{2}{*}{900} & & 84 & Anatase & 21 & & 12 \\
\hline & & & Rutile & 75 & & \\
\hline \multirow[t]{2}{*}{1000} & & 115 & Anatase & 51 & Anatase & - \\
\hline & & & Rutile & 82 & Rutile & 75 \\
\hline
\end{tabular}

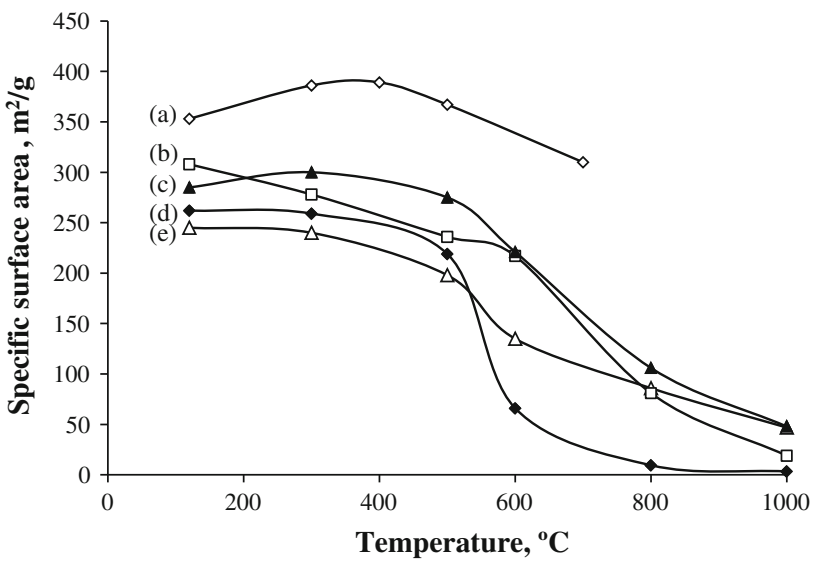

Fig. 3 Influence of thermal treatment on specific surface area of individual silica $(c)$ and titania $(d)$, and composites $\mathrm{SiO}_{2}-\mathrm{TiO}_{2}$ : coprecipitated $(b)$, core-shell $(e)$, prepared from sols $(a) . \mathrm{TiO}_{2}$ content in composites is 30 mas. $\%$
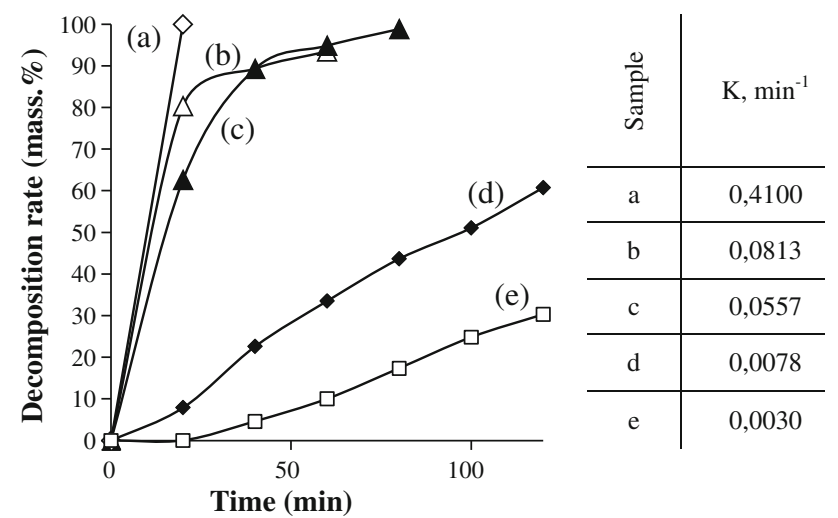

Fig. 4 Kinetics of Rhodamine $\mathrm{B}$ catalytic decomposition for $(a) \mathrm{TiO}_{2}$ sol, (b) core $\mathrm{SiO}_{2}-$ shell $\mathrm{TiO}_{2}\left(0,5 \% \mathrm{P}_{2} \mathrm{O}_{5} 800{ }^{\circ} \mathrm{C} 3 \mathrm{~h}\right)$, (c) core $\mathrm{SiO}_{2}-$ shell $\mathrm{TiO}_{2}\left(30 \% \mathrm{TiO}_{2} 700{ }^{\circ} \mathrm{C} 3 \mathrm{~h}\right),(d)$ co-precipitated $\left(30 \% \mathrm{TiO}_{2}\right.$ $\left.800{ }^{\circ} \mathrm{C} 3 \mathrm{~h}\right),(e)$ precipitated $\mathrm{TiO}_{2}\left(700{ }^{\circ} \mathrm{C} 3 \mathrm{~h}\right)$ by the sunlight, although the duration of the decomposition process already takes some hours.

At the same time individual titania, heat treated at $700{ }^{\circ} \mathrm{C}$, shows a low photocatalytic activity (Fig. 3, curve $\mathrm{e}, \mathrm{K}=0.003 \mathrm{~min}^{-1}$ ). The use of co-precipitated $\mathrm{SiO}_{2}$ $\mathrm{TiO}_{2}$ nanooxides can slightly increase the activity probably by increasing dispersivity. However, even under optimal conditions of composition and temperature the maximum decomposition rate constant is equal to $0.0078 \mathrm{~min}^{-1}$ (Fig. 3, curve d). The use of the "core $\mathrm{SiO}_{2}$-shell $\mathrm{TiO}_{2}$ " composites annealed under optimal conditions $\left(700{ }^{\circ} \mathrm{C}\right.$ $3 \mathrm{~h}$ ) increased the rate of reaction $\left(0.0557 \mathrm{~min}^{-1}\right)$. Introduction of modifying compounds, particularly, phosphoric acid $\left(0.5-5\right.$ wt. \% in terms of $\left.\mathrm{P}_{2} \mathrm{O}_{5}\right)$ to the composite "core $\mathrm{SiO}_{2}$-shell $\mathrm{TiO}_{2}$ " results in a significant increase of Rhodamine $\mathrm{B}$ decomposition rate. Under optimal conditions (0.5 wt. $\% \mathrm{P}_{2} \mathrm{O}_{5}$ and $\mathrm{T}=800{ }^{\circ} \mathrm{C}$ ), the reaction rate constant was $0.0813 \mathrm{~min}^{-1}$. The apparent advantage of the photocatalyst is the possibility of its re-use, so it can be easily separated from the substrate, that is not possible in the $\mathrm{TiO}_{2}$ sol case.

The "core $\mathrm{SiO}_{2}-$ shell $\mathrm{TiO}_{2}$ " composites can be used as catalysts for nifedipine kardiotropic series drugs synthesis $[25,26] . \mathrm{SiO}_{2}-\mathrm{TiO}_{2}$ nanooxides increase regioselectivity of Hantzsch reaction and can be used in synthesis of nifedipine and nitrendipine racemate. It was discovered that the greatest degree of activation of ethyl acetoacetate was observed for samples with a high content of $\mathrm{TiO}_{2}$ and "core $\mathrm{SiO}_{2}$-shell $\mathrm{TiO}_{2}$ " morphology. The use of $\mathrm{SiO}_{2}$ $\mathrm{TiO}_{2}$ nanooxides in the synthesis made in possible to optimize production conditions, namely to reduce the reaction temperature from $80{ }^{\circ} \mathrm{C}$ to room temperature, and improve the content of the main substance in the final product from 60 to $90-92 \%$ by HPLC. It is also shown that 
nanoscale metal oxides do not only help to improve the efficiency of simple commercially available chiral inductors, but serve as a new tool to increase stereoselectivity of multicomponent reactions. The study allowed to achieve an enantiomeric excess (ee) in the Biginelli reaction $84.3 \%$.

Electrorheological dispersions with $\mathrm{SiO}_{2}-\mathrm{TiO}_{2}$ nanocomposites (co-precipitated and with the "core $\mathrm{SiO}_{2}$-shell $\mathrm{TiO}_{2}$ " morphology) as fillers showed a fairly high electrorheological response: shear stress was 500-600 Pa at 20 wt. \% filler content. Comparison of electrorheological response of dried and calcined composite samples (complete lack of response from the latter) allows to refer them to materials which manifestation of electrorheological activity is caused by the presence of physically adsorbed and coordinatively bound water [27].

\section{Conclusion}

It is shown that the use of organomineral derivatives of titanium and silicon in the studied range of influencing factors permits obtain composite materials with a developed specific surface area, the value of which can vary widely. Introduction of structure-forming agents is particularly effective when sols are used as initial components.

The degree of components homogenization at the stage of mixing and the product morphology determine the nature and degree of titanium component crystallization.

Change of the specific surface area of the $\mathrm{SiO}_{2}-\mathrm{TiO}_{2}$ nanocomposite materials after heat treatment is determined mainly by the crystallization characteristics of the titaniumcontaining component and the content of the composite.

High photocatalytic activity of the "core $\mathrm{SiO}_{2}$-shell $\mathrm{TiO}_{2}$ " composite in Rhodamine $\mathrm{B}$ decomposition reaction, posibility to optimize some parameters for a number of reactions in the Biginelli and Hantzsch synthesis of kardiotropic drugs nifedipine series, their use as electrorheological fluid fillers have been ascertained.

Acknowledgments The authors are grateful to the Belarusian Republican Foundation for Fundamental Research for financial support (grants X10P-027, X12P-071).

\section{References}

1. Iler RK (1979) The chemistry of silica: solubility, polymerization, colloid and surface properties and biochemistry of silica. John Wiley and Sons, New York

2. Anwar NS, Kassim A, Lim HN, Zakarva SA, Huang NM (2010) Sains Malays 39:261

3. Inagaki M, Nakazawa Y, Hirano M, Kobayashi Y, Toyoda M (2001) Int J Inorg Mat 3:809-813

4. Yan H, Chunwei Y (2005) J Cryst Gr 274:563-573

5. Aguado J, Grieken R, Lopez-Munoz M-J, Marugan J (2006) Appl catalys 312:202-212

6. Macwan DP, Dave Pr N, Chaturvedi Sh (2011) J Mat Sci 46:3669-3686

7. Tyukova IS, Suvorova AI, Okuneva AI, Shishkin EI (2010) Polym Sci 52:564-570

8. Kholdeeva OA, Trukhan NN (2006) Rus Chem Rev 75:411-433

9. Murashkevich AN, Lavickaya AS, Barannikova TI, Zharsky IM (2008) J. Appl. Spectr. 75:724-728

10. Murashkevich AN, Alisienok OA, Zharsky IM (2011) Kin Cat 52:809-816

11. Murashkevich AN, Alisienok OA, Lavitskaya AS, Zharsky IM (2010) Sviridov read 6:48-55

12. Murashkevich AN, Lavitskaya AS, Alisienok OA, Zharskii IM (2009) Inorg Mat 45:1146-1152

13. Chen Sh, Liu H, Wang C et al (2012) Chem Ind Eng Progr 31:1052-1056

14. Chao X, Zili X, Qiujing Y, Baoyong X et al (2004) Mat Sci Ing 112:34-41

15. Ei-Toni AM, Yin S, Sato T (2006) J. Coll. Int. Sci. 300:123-130

16. Hu Ch, Yuchao T, Zheng J et al (2003) Appl Cat 253:389-396

17. Jun-ping M, Jin-sheng L, Guang-chuan L et al (2006) Trans. Nonferr. Met. Soc. Ch. 16:547-550

18. Li G, Bai B, Zhao XS (2008) Ind Eng Chem Res 47:8228-8232

19. Hu Sh, Li F, Fan Z (2012) Bull Korean Chem Soc 33:1895-1899

20. Murashkevich AN, Alisienok OA, Zharskii IM (2009) Sviridov read 5:161-168

21. Koltsov SI, Tuz TV (1991) Int. Inst High Edu Chem Chem Tech 34:90-95

22. Wilhelm P, Dietmar S (2007) J Photochem Photobiol A: Chem 185:19-24

23. Epling GA (2002) Chemosphere 46:561-566

24. Tanaka K, Padermpole K, Higanaga T (2000) Wat Res 34:234-327

25. Fedorova OV, Koryakova OV, Valova MS, Ovchinnikova IG, Titova YuA (2010) Kin Cat 51:566-573

26. Fedorova OV, Valova MS, Titova YuA, Ovchinnikova IG, Grishakov AN (2011) Kin. Cat. 52:226-233

27. Murashkevich AN, Alisienok OA, Zharsky IM (2012) Inorg Mat 48:1218-1312 